\title{
World travel with type 1 diabetes using continuous subcutaneous insulin infusion
}

\author{
ALEXANDER R CHARLTON, ${ }^{1,2}$ JESSICA R CHARLTON ${ }^{1,2}$
}

\begin{abstract}
Living with type 1 diabetes and using continuous subcutaneous insulin infusion (CSII), the authors travelled together for four months through 11 countries. Travelling with type 1 diabetes presents various added challenges. Personal experience of the challenges faced by the authors in relation to their diabetes are discussed along with the ways they were able to overcome these challenges. A review of general aspects one may encounter when travelling with type 1 diabetes and CSII follows. This provides an insightful overview for individuals living with type 1 diabetes intending to travel as well as healthcare professionals involved in providing care to those with type 1 diabetes intending to travel.

Br J Diabetes 2019:19:141-146
\end{abstract}

Key words: type 1 diabetes, travel, insulin, climate, altitude, flight, continuous subcutaneous insulin infusion, CSII, airport security, metabolism, physiology, glucose

\section{Background}

Living with type 1 diabetes and using continuous subcutaneous insulin infusion (CSII), the authors travelled together for four months through 11 countries. Those with type 1 diabetes are less likely to travel and there is great variation in professional advice (sometimes dangerous and often overcomplicated). ${ }^{1}$ For those who do manage to travel, it is generally a positive experience and enhances one's understanding of their own diabetes and selfmanagement. Travelling with type 1 diabetes presents various added challenges, which are reviewed here, so that they can be overcome.

\section{Experience of the authors}

The first challenge we faced was packing, deciding how much of the various required supplies to pack, how to divide them amongst our luggage, how many/what spares to carry, how to keep insulin at stable temperature, how to pack in order to comply with airport security requirements, how to protect the glass insulin vials from damage. We also had to ensure that we had letters about our dia-

University Hospitals of Leicester NHS Trust, Leicester, UK

Camp Charnwood Childrens' Diabetes Camp, Leicestershire, UK

Address for correspondence: Dr Alexander Charlton ENT Department, Leicester Royal Infirmary, Infirmary Square, Leicester LE1 5WW, UK

E-mail: alex.charlton@nhs.net

https://doi.org/10.15277/bjd.2019.224 betes and the need to carry our equipment as well as security requirements for the insulin pumps. Packing for four months' travel is difficult without diabetes, but we realised the additional challenges of trying to fit four months' supply of our diabetes paraphernalia, plus adequate spares and backup supplies. This was exacerbated by the fact that we used different insulin pumps which each had different associated paraphernalia - having the same equipment would have probably saved a considerable amount of space and simplified the process. In order to avoid the risk of loss or damage in hold luggage, our solution was to carry all diabetes paraphernalia in one item of hand luggage and share the other item of hand luggage for our personal belongings for travel.

\section{New Zealand}

The difficulty with starting our trip in New Zealand was the long duration of travel from the UK to New Zealand and the dramatic time difference. We reduced our basal insulin and made use of flash glucose monitoring to closely monitor glucose levels and make appropriate adjustments to basal insulin profiles - flash glucose monitoring allowing patterns to be identified much quicker than with finger prick glucose monitoring. We travelled around New Zealand for four weeks in a hired camper van. One challenge faced was that we had to hire a high-specification vehicle at greater expense in order to have a refrigerator for storage of our insulin. A lot of the activities we did were water-based in the ocean. During one trip to swim with wild dolphins there was such excitement and rushing to get into the water while the dolphins were around the boat that one of us jumped into the water with the insulin pump still on their person. The manufacturer states that it is "protected against the effects of temporary immersion in water under standardised conditions", so we were concerned for the well-being and performance of the pump following this.

Fiji

Our time in Fiji was mainly spent visiting various small islands. We therefore faced challenges of being surrounded by water. The climate is tropical, so during boat transit between islands, to keep our insulin cool we made use of the on-board fridges (stocked with vendible refreshments) with permission from the crew. On transfer from the large passenger boat to the individual accommodation, as well as on outings, we would travel on small wooden boats and disembark into the shallow water to walk onto land. These conditions created water exposure hazards for our electronic devices. We alleviated these risks to some extent by stashing electricals in dry bags whenever practicable - not always practical when physically connected to an insulin pump or requiring frequent access to a 
blood glucose monitor. On the islands' accommodation there was typically a single refrigerator, which we would ask staff to use to store our insulin for the duration of our stay. This was a source of constant anxiety for its safety, concerned that someone may remove it from the fridge, damage it or dispose of it or, indeed, that we would forget to take the insulin with us on departing.

The island habitations were so remote that they relied on their own small-scale means of generating electricity. This resulted in frequent loss of electrical power - another cause for concern regarding our insulin's well-being - but also causing difficulties with charging our blood glucose monitoring handsets. For this, we fortunately had had the foresight to take a solar powered battery from which we could charge our devices. The heat (and resulting sweat) and the frequent water exposure in Fiji meant that flash glucose sensors we had on our upper arm would come off prematurely due to the adhesive failing - a problem which persisted in the hotter climates throughout our journey (I understand that Accucheck have since modified their adhesive to address this issue).

On more than one occasion we woke in the night to find rodents attempting to devour our stash of sweets for treating hypoglycaemia. This risked damage to our bags, contamination of our 'hypo treatment' and depletion of supplies, with subsequent danger of untreated hypoglycaemia. This problem was exacerbated by the difficulty in obtaining appropriate hypoglycaemia treatments in such remote locations with limited provisions. We had packed enough 'hypo treatment' that we were sustained during this part of the trip.

On exiting Fiji, airport security officials threatened to confiscate our insulin because it was in a clear plastic box rather than a clear plastic bag. Fortunately, we were able to explain the medical need for the insulin and they permitted us (and our insulin) to continue the journey.

\section{United States of America}

From Fiji, we flew east to Los Angeles. Again, there was a significant time difference, so we monitored our glucose levels more frequently and adjusted basal insulin rates according to patterns detected from our flash glucose monitoring. Getting a shuttlebus from the airport terminal to the car rental office, we left an item of hand luggage on the bus which contained most of our diabetes paraphernalia, including all of our insulin. After disembarking the bus, we realised we did not have this bag and managed to retrieve it before the bus left, but this was a near miss and, had we lost the bag, it would have been catastrophic. We packed our crucial diabetes paraphernalia in a hand luggage bag in order to keep it safe and avoid the risks of loss and damage that may occur with hold luggage, but this incident emphasises the importance of splitting gear across at least two different bags to mitigate the impact of a lost or stolen bag.

Another potential problem occurred when we drove our rental car to Disneyland and lost the car key, resulting in a significantly longer day out than anticipated as we waited for a rescue service, had the car towed to the nearest branch of the rental company (in the opposite direction to our accommodation), before driving the long journey back to our accommodation. In total this took our day trip from approximately 7 hours to 17 hours. Our experience has taught us to always carry more supplies than anticipated to be required, so we did not encounter any problems as a result of the delays, but there was the potential to run out of insulin in a pump or use up all our hypo treatment or indeed use all available test strips. Throughout our trip, a great deal of attention and planning was required every time we went on an outing or trip to ensure we had all the equipment and supplies we would need and extra in case of unexpected circumstances.

\section{Costa Rica}

In the tropical climate of Costa Rica we noticed increased insulin sensitivity and subsequent risk of hypoglycaemia due to the heat. Treatments for hypoglycaemia were harder to come by as we were staying in rural areas. Thankfully, we hired a car during our time in Costa Rica so could easily reach larger shops to buy hypo treatments. Dosing difficulties persisted throughout Central/South America because of our unfamiliarity with the products available and language barrier when reading the nutritional information. This was a challenge for carbohydrate counting generally, throughout the trip, and particularly in Central/South America as we ate many new and unfamiliar foods. Again, close monitoring of blood glucose was key.

\section{Panama}

On crossing the land border from Costa Rica to Panama, there were several desks requiring various documents and payments. Combined with strained communication from language barriers, this demanded our full attention. It seems that, while we were distracted, one of our blood glucose meters was stolen. We also found that one of our glucose meters would not charge when plugged into mains power in several countries due to compatibility issues. Fortunately these did not cause problems because we had taken spares, but it highlights the importance of carrying spare equipment due to risks of loss, theft or failure.

\section{Colombia}

During a long coach journey through the mountains in Colombia, the coach was stopped and searched by a police group. This included a search of each individual on the coach as well as their belongings. Although we did not encounter any problems, we were anxious that the large quantities of insulin and diabetes paraphernalia we were carrying could be misconstrued as suspect goods. Airport security staff were also intimidating, refusing to let us past airport security without passing through the whole-body scanner. In order to continue our journey, we disconnected our pumps and handed them to the security staff to examine and swab and then passed through the whole-body scanner without our pumps. This is not recommended, as the insulin pump should ideally remain connected whenever possible.

\section{Ecuador}

We crossed the land border into Ecuador at an altitude of approximately 2950 metres. This is around the time altitude sickness affected us. We noticed increased insulin requirements and more 
time for boluses to take effect. During our time here and throughout the Andes we did plenty of hiking and observed that our insulin requirements were greater, despite the exertion. We responded by titrating our basal and bolus ratios up, but found our glucose levels to be more erratic and difficult to control. Some of the effects of altitude sickness were easy to confuse with symptoms of hypoglycaemia, such as 'fuzzy headedness', lethargy, tachycardia/palpitations and breathlessness. Once again, our strategy to tackle this was increased intensity of glucose monitoring.

Given the danger of being disconnected from the CSII for a prolonged time, it was very concerning when we found ourselves locked out of the kitchen where our insulin was stored in the refrigerator, unable to contact any of the accommodation staff, with a pump which was exhausted of insulin. Fortunately, we were carrying a back-up rapid-acting insulin pen and, thinking outside the box, we were able to draw up insulin from this to a new pump cartridge. Clearly it would have been wise to keep a vial of insulin with us and/or ensured we had access to the refrigerator, but with language barriers and thinking about everything else involved in travelling, this kind of forethought can be difficult.

\section{Peru}

In Peru we undertook the Lares trek, reaching an altitude of 4550 metres. This highlighted the challenges with altitude already discussed and these were perpetuated by the variable exertion and diet we had during the trek. We also had to carry bags which were made heavier by all the necessary supplies to manage our diabetes. To make matters harder, discrepancies were identified between our flash glucose monitors and finger prick blood glucose monitors. This added to the difficulty of decision-making about insulin dosing and carbohydrate intake in the already hostile circumstances.

\section{Bolivia}

Having crossed from Peru into northern Bolivia, then flown from La Paz to Uyuni, we explored the salt flats while journeying to the Chile border. We stayed overnight in a residence made completely of salt which was fascinating, but very cold. Blood glucose levels were unexpectedly rising, and the efficacy of insulin boluses appeared diminished and variable. By this time we had been carrying our insulin for over three months, being exposed to extremes of temperature, and it occurred to us that this may have affected its efficacy. We endeavoured to use Frio wallets when journeying and placing the insulin in a refrigerator for the duration of our stay at each location, but exposure to variable temperatures still occurred.

\section{Chile}

We crossed into Chile and spent several days in the Atacama Desert before flying to Santiago and onwards to Buenos Aires. This was the period when we discovered cracks in some of the glass insulin cartridges used in our Roche Insight insulin pump. On several occasions, leakage of insulin (with its distinctive odour) was noted from this insulin pump. We postulated this may have caused variable insulin delivery and been another reason for erratic and unpredictable blood glucose control in latter times. Very few insulin pumps use glass vials, and this highlights one drawback to using this configuration of insulin pump while travelling, suggesting that one of the insulin pumps utilising plastic insulin reservoirs may be safer.

\section{Argentina}

Our destination before returning home to the UK was Buenos Aires. Our time here was marked (for one of us) by unusually low blood glucose levels requiring much greater than usual quantities of fastacting carbohydrates to amend. The most significant environmental change prior to this was a return from high altitude to close to sea level. We therefore considered that this may have been a rebound phenomenon following exposure to high altitude for several weeks.

\section{Review of pertinent aspects of travel Air travel}

When boarding for air travel it is important to consider the distribution of diabetes supplies in hand luggage and hold luggage. Insulin, at least, must be carried in hand luggage as exposure to extreme cold in the hold could affect its potency. We opted to carry all diabetes supplies and paraphernalia in our hand luggage in case of required access due to delays or emergencies, and to avoid loss or damage which may occur with hold luggage. Some airlines will permit extra hand luggage allowance for this purpose, so consider contacting in advance.

Crossing into a different time zone with an insulin pump, one should simply change the time setting of the insulin pump to the destination time on departure. This may result in over or under delivery of insulin in the short term, so frequent blood glucose testing is key. We made prudent use of flash glucose monitoring when entering new time zones. ${ }^{2}$ For those using multiple daily injections (MDI) of insulin, http://diabetestravel.org/ has useful algorithms for insulin adjustment depending on whether travelling east or west. ${ }^{3}$

During air travel one is usually sedate, with a reduced metabolic rate and increased insulin resistance, and should therefore consider applying an increased temporary basal rate.

During take-off, reduced atmospheric pressure can cause bubbles to form in the insulin chamber and/or inadvertent insulin delivery. ${ }^{4}$ Thus, we recommend the pump is disconnected and stopped during take-off. Once at cruising altitude, the chamber and tubing should be primed to remove visible bubbles before reconnecting. Priming should be repeated upon landing. It follows that insulin pens for those using MDI may also develop bubbles. Care should be taken to express these prior to injecting a bolus when flying to avoid delivering less insulin than intended.

Dehydration frequently occurs during air travel and contributes to the risk of venous thromboembolism (VTE). ${ }^{5}$ Diabetes is an independent risk factor for $\mathrm{VTE}^{6}$ and, during hyperglycaemia, polyuria may exacerbate dehydration and further compound the risk of VTE as well as diabetic ketoacidosis. ${ }^{7}$ It is therefore strongly advised to drink plenty of fluids and avoid alcohol and caffeine (due to their diuretic effects) during the flight.

It is also worth noting that a combination of increased background noise and reduced air pressure and humidity alter the 
sense of taste during flight. ${ }^{8}$ Airlines tend to make dishes sweeter and saltier in order to improve palatability at altitude. Higher fat content is also used to improve preservation of meals. These nutritional modifications may affect insulin requirements - there are likely to be higher carbohydrate quantities and a longer duration of bolus delivery may be beneficial. We would suggest avoiding 'diabetic' meal options as the carbohydrate content is unpredictable and often very low, which has been shown to risk hypoglycaemia. ${ }^{9}$

\section{Airport security}

People with diabetes have reported feelings of insecurity, fear, prejudice, rejection and shame while transiting through airport security. ${ }^{10}$ Several factors create this negative experience, including the hostility of the environment, language barriers, poor understanding among airport security staff and a lack of clear or unified advice about insulin pumps and airport security technologies. ${ }^{11}$

Airport technologies can cause damage to insulin pumps through $x$-ray radiation and magnetic fields. Individual insulin pump manufacturers should be contacted for advice, but there is consensus that pump exposure to walk-through metal detectors is safe..$^{12}$ Unless specified otherwise by the manufacturer, we recommend avoiding pump exposure to $x$-ray machines and wholebody scanners (Figure 1). Insulin pens are safe to pass through the $x$-ray machines. For blood glucose monitoring technologies such as flash and continuous glucose monitoring devices, the same advice applies as for insulin pumps.

Figure 1. Airport security technologies and insulin pumps. $\checkmark=$ safe $\boldsymbol{x}=$ unsafe.

Reproduced with permission from Rachel Humphrey of the Juvenile Diabetes Research Foundation (www.jdrf.org.uk).

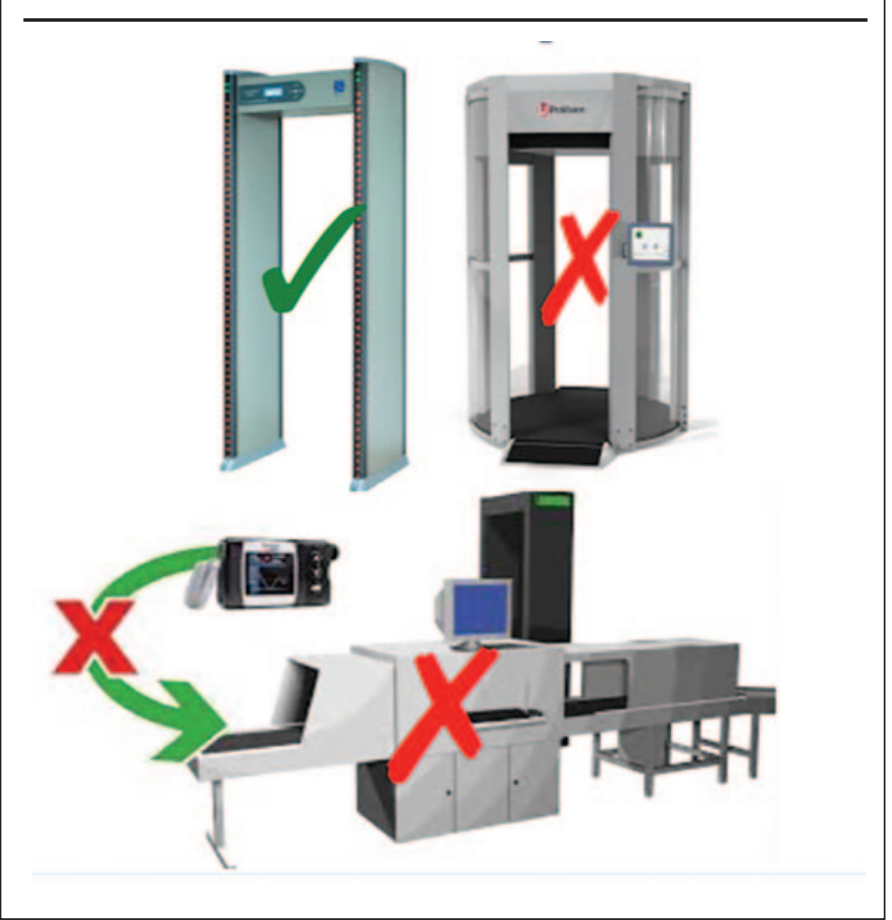

There is the potential for significant harm to occur when security staff insist on insulin pump removal or insist that the insulin pump must pass through the $x$-ray machine. This is highlighted by the experience of a family travelling through Dubai airport. ${ }^{13}$ This should always be avoided. Clearly, the same applies to glucose monitoring devices - these should not need to be removed for airport security.

For the purpose of smooth transit through airport security one should carry a letter from one's diabetes healthcare team outlining the diagnosis, required equipment/medication, the hazards of airport security technologies and the pump/equipment serial numbers. The Civil Aviation Authority also has a downloadable 'card' available online, which can be printed off and carried, outlining information for both passengers and security officers regarding the handling of diabetes medical devices. ${ }^{14}$ Guidance on 'Using diabetes technology at the airport' is also available on the Diabetes UK website. ${ }^{15}$

\section{Altitude}

People with type 1 diabetes have similar success rates to diseasefree individuals when tackling high altitude expeditions, although it is important to be healthy, physically fit, well prepared and capable of self-management. These expeditions are an effective form of physical activity - encouraged to all with diabetes - and can boost self-management skills. ${ }^{16,17}$

Although people with diabetes are no more likely to develop acute mountain sickness, it is more hazardous when it occurs: its symptoms can mask hypoglycaemia, there is an increased risk of ketonuria and ketoacidosis, and it contributes to hyperglycaemia. The risk of ketoacidosis is compounded by poor performance of glucose meters, which tend to underestimate high blood glucose, ${ }^{18,19}$ and the use of acetazolamide (used to treat acute mountain sickness), which causes excretion of bicarbonate and therefore diminished adaptive buffering of acidosis. ${ }^{20}$ Gradual ascent with time for acclimatisation protects from these effects.

Increased insulin resistance occurs in correlation with increasing altitude. The physiological processes behind this are summarised in Figure $2 .{ }^{21}$ Interestingly, there is also an exaggerated stress response to exercise, such that insulin requirements tend to increase despite the insulin-sensitising effects of exercise. ${ }^{22}$ The other physiological effects which must be considered with diabetes are summarised in Figure 3.23

\section{Climate}

Various climates may be encountered when travelling abroad. Temperature can have significant impacts for the person with diabetes. Hot climates cause more rapid insulin absorption and may increase insulin sensitivity. This can cause hypoglycaemia without appropriate adjustments to insulin delivery. Using prolonged boluses can counteract the rapidity of absorption and, for MDI users, reducing the bolus amount and monitoring blood glucose, with potential need for a second bolus later. Temporary basal reductions may also help reduce the incidence of hypoglycaemia. Those with diabetes are also at higher risk of developing febrile illnesses in tropical climates. ${ }^{24}$ 
Figure 2. Physiological effects of altitude on glucose homeostasis. ${ }^{21}$ Reproduced with permission from the American Diabetes Association

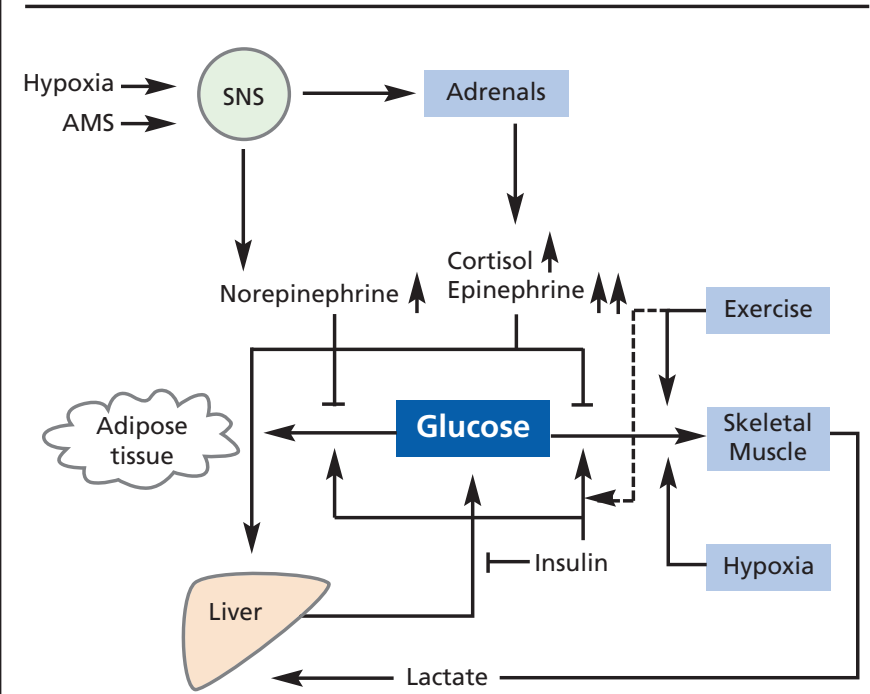

AMS, acute mountain sickness; SNS, sympathetic nervous system.

Conversely, cold climates can cause slower insulin absorption, so it is important to allow sufficient time for insulin boluses to take effect before administering further doses of insulin and 'overcorrecting'. One must also be wary of suddenly increased insulin absorption on entering a heated building and erratic/unpredictable insulin absorption when undertaking exercise in the cold. Hypoglycaemia is particularly dangerous in cold climates, as the sweating predisposes to hypothermia. ${ }^{23}$ Frostbite, skin fissures and secondary infections are also dangers for those with diabetes. ${ }^{23}$

In unfamiliar climates, dysregulation is likely to occur, so it is important to increase the frequency of blood glucose testing something which is often poorly done by travellers with diabetes. $^{24}$

Extreme temperatures also create challenges for insulin storage. Access to a refrigerator is available in most hot climate parts of the world but, otherwise, Frio medical storage devices are effective. It is also important to remember to avoid overheating of the insulin in the pump and tubing (or insulin pens) by avoiding exposure to direct sunlight and hot surfaces (including your own body surface). In comparison, in cold climates one can keep insulin and tubing (or insulin pens) against the skin and well insulated to avoid exposure to extreme cold.

Apart from insulin, glucose monitoring equipment can perform poorly at extremes of temperature and at high humidity. Function is generally normal at $15-35^{\circ} \mathrm{C}$ but may be inaccurate or cease to function completely at extremes. As well as protecting equipment from temperature extremes, test strips should be kept from direct sunlight (ultraviolet light) and high humidity, control solution should be used frequently and a low threshold for ketone testing adopted.
Figure 3. Physiological effects of altitude in relation to diabetes. ${ }^{23}$ Reproduced with permission from John Wiley and Sons

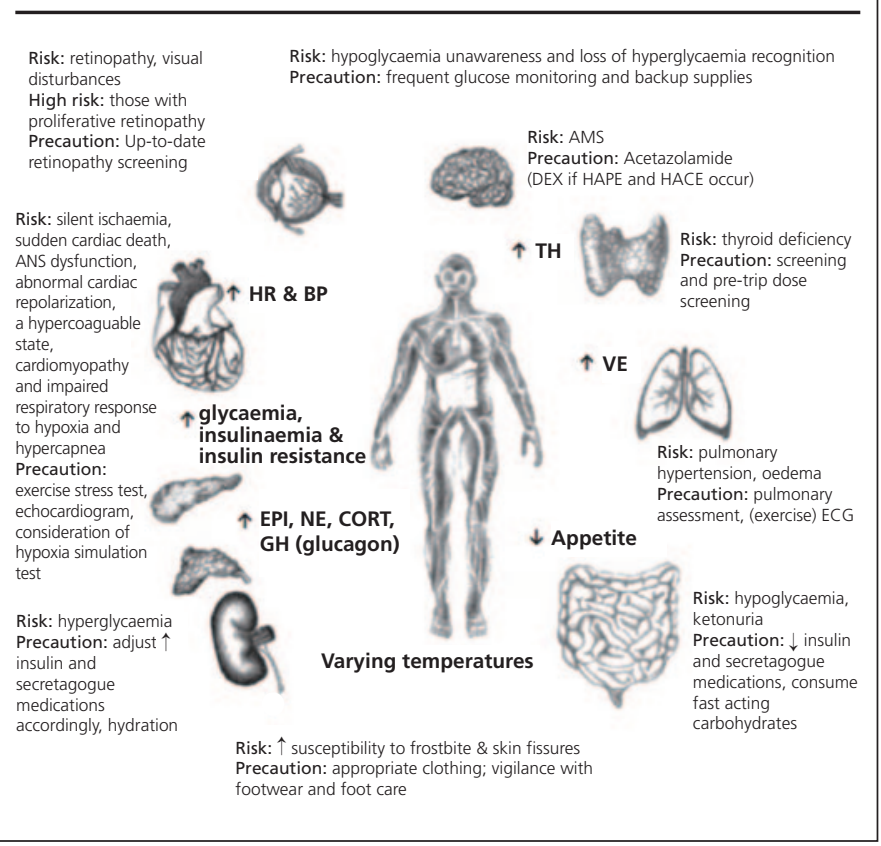

\section{Conclusion}

Type 1 diabetes presents various challenges and hazards for the global traveller. For travel to be safe, it is crucial that we continue to develop knowledge and understanding about the factors affecting the traveller with type 1 diabetes. Furthermore, dissemination of this information is key to promoting safe travel and dignity for those with type 1 diabetes when interacting with security and travel professionals. Our experience and review of relevant literature brings to light many of these factors, making global travel more accessible, especially for those using CSII. Box 1 provides a summary of the key learning points for persons with diabetes and for healthcare professionals.

\section{Conflict of interest None Funding None}

\section{References}

1. Gill GV, Redmond S. Insulin treatment, time-zones and air travel: a survey of current advice from British Diabetic Clinics. Diabet Med 1993;10(8):764-7. https://doi.org/10.1111/j.1464-5491.1993.tb00161.x

2. Chandran M, Edelman SV. Have insulin, will fly: diabetes management during air travel and time zone adjustment strategies. Clin Diabetes 2003;21(2):82-5. https://doi.org/10.2337/diaclin.21.2.82

3. Kerr D, Martinez J. Time zones [online]. 2015. Available at: https://diabetestravel.org/time-zones/ (accessed 3 May 2019).

4. King BR, Goss PW, Paterson MA, Crock PA, Anderson DG. Changes in altitude cause unintended insulin delivery from insulin pumps: mechanisms and implications. Diabetes Care 2011;34(9):1932-3. https://doi.org/10.2337/dc11-0139

5. Chee $\mathrm{YL}$, Watson HG. Air travel and thrombosis. Br J Haematol 2005 130(5):671-80. https://doi.org/10.1111/j.1365-2141.2005.05617.x

6. Ageno W, Becattini C, Brighton T, Selby R, Kamphuisen PW. Cardiovascular risk factors and venous thromboembolism. Circulation 2008;117(1): 93-102. https://doi.org/10.1161/CIRCULATIONAHA.107.709204 


\section{Box 1 Key learning points}

\section{Persons with diabetes}

\section{Before travel}

- $\quad$ Research available insulins and healthcare arrangements at destination(s).

- Ensure adequate travel insurance is in place which will cover diabetes-related incidents.

- Contact your airline in advance to enquire about additional hand luggage allowance for medical equipment.

- Aim for stable glycaemic control prior to embarking on a trip.

- Meet with specialist diabetes team prior to trip and engage them in preparing and planning for the trip.

- Pack at least double the anticipated supplies required for the trip and divide this among different bags if possible (in case of loss/theft)

- $\quad$ Pack/carry diabetes equipment/paraphernalia in hand luggage to avoid loss or damage during flights.

- Always pack/carry insulin in hand luggage as exposure to extreme cold in the aeroplane hold damages the insulin.

- $\quad$ Seriously consider the risks associated with exposure to high altitude and ensure adequate understanding and preparation.

- $\quad$ Pack/carry a letter from your specialist diabetes team stating the following: diagnosis, required equipment and medication, hazards of airport security technologies, insulin pump serial number.

- Carry a Civil Aviation Authority card for diabetes medical devices

- To ensure insulin is stored at an appropriate temperature, enquire about refrigerator availability at accommodation and make use of Frio medical storage devices.

\section{During travel}

- It should not be required to remove the insulin pump at any point while passing through airport security.
- Avoid passing insulin pump through $\mathrm{x}$-ray machines or whole-body scanners as these may cause damage.

- On flight departure, change the time setting of the insulin pump to the destination time - ensure frequent blood glucose monitoring. Flash or continuous glucose monitoring may be useful when crossing time zones.

- Use algorithms from http://diabetestravel.org/ for insulin adjustment when crossing time zones if using multiple daily injections.

- Consider using increased temporary basal rate during air travel (sedate, reduced metabolic rate, increased insulin resistance)

- Disconnect insulin pump during take-off due to risk of inadvertent insulin delivery. Prime infusion set once at cruising altitude to remove any visible bubbles.

- Note that airline meals often have increased sugar and fat content.

- $\quad$ Airline 'diabetic' meals have lower carbohydrates and may increase the risk of hypoglycaemia.

- Drink plenty of fluids and avoid alcohol and caffeine during flights, as dehydration increases risk of VTE and DKA.

- $\quad$ Store insulin at an appropriate temperature, in refrigerators where available, otherwise a Frio medical storage device.

- $\quad$ Avoid using acetazolamide for acute mountain sickness as it may increase the risk of DKA.

- Where possible, ascend gradually and allow time for acclimatisation to minimise risk.

- Consider increasing basal and/or bolus insulin as insulin resistance increases with altitude.

- In hot climates, consider reducing basal insulin as insulin sensitivity may be greater. Also consider using prolonged boluses to counteract the increased absorption rate of insulin.

- In cold climates, appreciate that insulin boluses may take longer to be effective. Avoid 'over-correcting' when blood glucose has not reduced as quickly as expected from a bolus of insulin.

- Increase frequency of blood glucose monitoring in unfamiliar climates, as dysregulation is likely to occur.

- Glucose monitoring equipment can be unreliable at extremes of temperature - store at $15-35^{\circ} \mathrm{C}$ where possible and avoid exposure to humidity.

\section{Healthcare professionals}

- Support patients to travel.

- $\quad$ Provide prescription for adequate supplies for double the anticipated quantity required for the proposed trip.

- $\quad$ Signpost patients to resources such as http://diabetestravel.org/ and https://www.diabetes.org.uk/guide-to-diabetes/life-withdiabetes/travel

- $\quad$ Try to arrange appointments at appropriate timing before and after the trip.

- $\quad$ Provide a point of contact for advice or support during travel.

- Where possible, provide spare blood glucose monitor, insulin pump and/or long-acting and short-acting insulin pens.

- $\quad$ Provide capillary blood ketone testing equipment.

- $\quad$ Provide signed letter outlining diagnosis, required equipment and medication, hazards of airport security technologies and insulin pump serial number.

- Provide advice and guidance on regimes for modifying insulin.

- $\quad$ Provide verbal and written information on sick day rules in case of illness.

- Where possible, provide guidance on carbohydrate counting for typical foods of the travel destination.

- If a trip at high altitude is planned, consider pre-trip screening and optimisation of relevant physiology as per Figure 3
7. Tashima CK, Fillhart M, Cunanan A. Jet lag ketoacidosis. JAMA 1974;227(3):328. https://doi.org/10.1001/jama.227.3.328

8. Spence C. Tasting in the air: a review. Int J Gastronomy Food SCi 2017:9:10-5. https://doi.org/10.1016/j.ijgfs.2017.05.001

9. Pavela J, Suresh R, Blue RS, Mathers CH, Belalcazar LM. Management of diabetes during air travel: a systematic literature review of current recommendations and their supporting evidence. Endocr Pract 2018, 24(2):205-19. https://doi.org/10.4158/EP171954.RA

10. de Cássia Sparapani V, Jacob E, Nascimento LC. What is it like to be a child with type 1 diabetes mellitus? Pediatr Nurs 2015;41(1):17-23.

11. McGhee K. Diabetes and air travel: ensuring security, promoting dignity. Int Airport Rev 10 February 2017.

12. Nassar AA, Cook CB, Edelman S. Diabetes management during travel. Diabetes Manage 2012;2(3):205. https://doi.org/10.2217/DMT.12.23

13. International Airport Review: Rachel Humphrey (2016). Held in an airport for 2 hours because my son had an insulin pump [online] https://www.internationalairportreview.com/article/24871/open-letter-dubai-international-airport-diabetes-insulin-pump/(accessed 2 May 2019)

14. Civil Aviation Authority (Caa.co.uk). 2019. Available from: https://www.caa.co.uk/uploadedFiles/CAA/Content/Standard_Content/P assengers/Before you fly/Health/CAA AOA MedicalDeviceAwarenessCard.pdf (accessed 21 August 2019)

15. Diabetes UK. Using diabetes technology at the airport. 2019. Available from: https://www. diabetes.org.uk/professionals/position-statements-reports/diagnosis-ongoing-management-monitoring/using-diabetes-technology-at-the-airport (accessed 21 August 2019).

16. Moore K, Vizzard N, Coleman C, McMahon J, Hayes R, Thompson CJ. Extreme altitude mountaineering and type 1 diabetes; the Diabetes Fed- eration of Ireland Kilimanjaro Expedition. Diabetic Med 2001;18(9):74955. https://doi.org/10.1046/j.0742-3071.2001.00568.x

17. Brubaker PL. Adventure travel and type 1 diabetes: the complicating effects of high altitude. Diabetes Care 2005:28(10):2563-72. https://doi.org/10.2337/diacare.28.10.2563

18. Fink KS, Christensen DB, Ellsworth A. Effect of high altitude on blood glucose meter performance. Diabetes Technol Ther 2002;4(5):627-35. https://doi.org/10.1089/152091502320798259

19. Giordano B, Thrash W, Hollenbaugh L, et al. Performance of seven blood glucose testing systems at high altitude. The Diabetes Educator 1989; 15(5):444-8. https://doi.org/10.1177/014572178901500515

20. Moore K, Thompson C, Hayes R. Diabetes and extreme altitude mountaineering. Br J Sports Med 2001;35(2):83. https://doi.org/10.1136/ bjsm.35.2.83

21. de Mol P, de Vries ST, de Koning EJ, Gans RO, Bilo HJ, Tack CJ. Physical activity at altitude: challenges for people with diabetes: a review. Diabetes Care 2014:37(8):2404-13. https://doi.org/10.2337/dc13-2302

22. de Mol P, de Vries ST, de Koning EJ, Gans RO, Tack CJ, Bilo HJ. Increased insulin requirements during exercise at very high altitude in type 1 diabetes mellitus. Diabetes Care 2011;34(3):591-5. https://doi.org/ 10.2337/dc10-2015

23. Mohajeri S, Perkins BA, Brubaker PL, Riddell MC. Diabetes, trekking and high altitude: recognizing and preparing for the risks. Diabet Med 2015;32(11):1425-37. https://doi.org/10.1111/dme.12795

24. Driessen SO, Cobelens FG, Ligthelm RJ. Travel-related morbidity in travelers with insulin-dependent diabetes mellitus. J Travel Med 1999;6(1):12-15. https://doi.org/10.2310/7060.1999.00004 